\title{
Pengelolaan Hutan Bersama Multistakeholder melalui Pengembangan Agroforestry Kopi Organik di Kawasan Hutan Darajat Kabupaten Garut
}

\author{
Okke Rosmaladewi $^{1}$, Ibrahim Danuwikarsa ${ }^{2}$, Maraden Panggabean ${ }^{3}$ \\ ${ }^{1}$ Universitas Islam Nusantara \\ ${ }^{2}$ Universitas Islam Nusantara \\ ${ }^{3}$ Star Energy Geothermal Darajat II.Ltd \\ okkerosmaladewi@uninus.ac.id
}

\begin{abstract}
Abstrak
Salah satu penyebab bencana lingkungan yang terjadi diakibatkan alih fungsi kawasan hutan di daerah hulu aliran sungai. Seperti di kawasan hutan lindung Darajat Kabupaten Garut, alih fungsi Kawasan hutan menjadi lahan pertanian hortikultura terjadi secara cepat dan massif. Hal ini menyebabkan kerusakan lingkungan, pencemaran lingkungan dan rawan bencana alam seperti banjir longsor dan kebakaran hutan. Dengan semakin menurunnya daya dukung sumber daya hutan tersebut, maka diperlukan system pengelolaan kawasan hutan yang komprehensif, partisipatif dan berkelanjutan dengan pendekatan kemitraan, pengembangan ekonomi ,kelestarian lingkungan dan melibatkan stakeholder.

Pengelolaan Hutan Bersama Multistakeholder melalui pengembangan Agroforestry Kopi Organik merupakan salah satu alternatif dalam mengurangi alih fungsi kawasan hutan ,meningkatkan konservasi lingkungan dan mengurangi resiko bencana alam. Program yang dilaksanakan berdasarkan kemitraan pihak perguruan tinggi melalui pengabdian masyarakat, pihak perusahaan melalui program Corporate Sosial Responcibility, PERHUTANI KPH Garut, dan Lembaga Masyarakat Desa Hutan.

Program dilaksanakan secara terintegrasi dimulai dari inventarisasi sumberdaya alam \& hutan, Pemetaan kondisi sosial ekonomi masyarakat desa hutan, perencanaan bersama pengelolaan kawasan hutan dengan melibatkan stakeholder, melaksanakan pengelolaan lingkungan berbasis masyarakat, rehabilitasi dan konservasi di lahan yang kritis melalui alih komoditas alih lokasi dan alih profesi . Pendampingan teknis dan sosial, Monitoring dan evaluasi secara bersama dan berkala serta pengamanan kawasan hutan secara bersama. Semua itu dilaksanakan untuk mengembalikan fungsi kawasan hutan menjadi hutan lestari dan siaga bencana.
\end{abstract}

Kata Kunci : Kawasan Hutan Lindung, Kemitraan,Multistakeholder,Agroforestry

\section{PENDAHULUAN}

Kawasan hutan adalah wilayah tertentu, yang ditunjuk dan ditetapkan oleh pemerintah untuk dipertahankan keberadaannya sebagai hutan tetap. Berdasarkan Undang-Undang Nomor 41 Tahun 1999 tentang Kehutanan, kawasan hutan dibagi kedalam kelompok hutan konservasi, hutan lindung dan hutan produksi. Hutan konservasi adalah kawasan hutan dengan ciri khas tertentu, yang mempunyai fungsi pokok pengawetan keanekaragaman tumbuhan dan satwa serta ekosistemnya. Hutan lindung adalah kawasan hutan yang mempunyai fungsi pokok sebagai perlindungan sistem penyangga kehidupan untuk mengatur tata air, mencegah banjir, mengendalikan 
erosi, mencegah intrusi air laut, dan memelihara kesuburan tanah. Dan hutan produksi adalah kawasan hutan yang mempunyai fungsi pokok memproduksi hasil hutan.

Berdasarkan Statistik Kementrian Lingkungan Hidup dan Kehutanan tahun 2017, Luas Kawasan Hutan di Jawa Barat Berdasarkan SK Menteri Kehutanan no 195/KPTS/ 2003, Luas Kawasan Hutan Konservasi $132.180 \mathrm{Ha}$ Hutan Lindung 291.306 Ha dan Hutan Produksi 202966 Ha. Dan luas Kawasan Hutan di Kabupaten Garut 107.560,42 Ha.

Kawasan Hutan Darajat terletak di dalam kawasan Cagar Alam Papandayan dan Hutan Lindung pada ketinggian 1.750-2.000 m dpl termasuk ke dalam wilayah administrasi Kabupaten Garut Provinsi Jawa Barat. Kawasan Hutan Darajat merupakan hutan tropis dataran tinggi yang memiliki keanekaragaman hayati yang sangat tinggi dengan struktur ekosistem yang kompleks.

Berdasarkan hasil observasi bahwa tutupan lahan di Kawaan Hutan Gunung Darajat berupa kawasan hutan dengan kerapatan tanaman yang rendah. Hal ini terjadi karena banyaknya alih fungsi lahan dari hutan lindung menjadi lahan pertanian hortikultura yang dikelola masyarakat secara konvensional dan intensif. Kondisi ini sangat membahayakan lingkungan karena dilakukan dengan mengurangi vegetasi pohon hutan dan tumbuhan bawah, dan diganti dengan tanaman hortikultura. ( Rosmaladewi, 2015)

Kondisi kerusakan kawasan hutan tersebut terjadi dipicu oleh pertumbuhan penduduk dan aktivitas sosial ekonomi masyarakat yang tinggal disekitar kawasan hutan lindung yang semakin mendesak dan merambah kawasan hutan konservasi. Masyarakat menanam tanaman hortikultura pada lahan yang kritis dengan tingkat kemiringan tinggi. Kondisi ini sangat berbahaya karena daerah tersebut menjadi rawan bencana alam seperti erosi, longsor dan banjir. ( Rosmaladewi, 2017)

Berdasarkan hal tersebut, maka pengelolaan lingkungan di kawasan hutan Darajat perlu mendapat perhatian dari semua pihak. Pemerintah dapat mendorong upaya kerjasama antar stakeholder dalam pengelolaan lingkungan khususnya dalam pengelolaan sumber daya hutan dan upaya rehabilitasi \& konservasi lingkungan sebagai upaya preventif penanggulangan bencana.

Apabila penanganan lingkungan ini tidak segera mendapatkan penanganan dari berbagai pihak, dan hanya mengandalkan upaya dari BKSDA dan Perhutani KPH Garut saja, maka akan berdampak terjadinya degradasi sumberdaya hutan yang terus menerus, dan masyarakat yang tinggal di kawasan hutan semakin tidak menyadari bahwa aktivitas mereka dalam pengelolaan lingkungan hutan berkontribusi terhadap bencana alam yang akan terjadi.

Pengelolaan kawasan hutan merupakan masalah bersama, untuk meningkatkan kelestarian fungsi dan sumber daya hutan sangat ditentukan oleh kemantapan kawasan hutan, kejelasan peraturan dan pengelolaannya. Untuk hal tersebut maka Pengembangan Agroforestry kopi organik dikawasan hutan Darajat sangat penting untuk dilaksanakan sebagai salah satu cara dalam melaksanakan rehabilitasi, revitalisasi dan mencegah alih fungsi kawasan hutan lindung Darajat.

Sebagaimana dijelaskan oleh Supriadi dan Pranowo (2015) Agroforestry dijadikan upaya dalam mengatasi kebutuhan akan lahan pertanian dengan tetap mempertahankan fungsi hutan dan lingkungan, sedangkan kopi organik adalah kopi yang diolah dan diproduksi tanpa menggunakan bahan-bahan anorganik yang mencemari lingkungan seperti pestisida sintetik dan pupuk sintetik dan ditanam sesuai dengan Good Agriculture Practices (GAP) sehingga kopi organik diyakini lebih aman untuk dikonsumsi.

\section{Pengelolaan Hutan Bersama} Multistakeholder melalui Pengembangan Agroforestry Kopi Organik dilaksanakan dengan meningkatkan sinergitas dan optimalisasi Multistakeholder yang peduli terhadap kelestarian kawasan hutan seperti pihak perguruan tinggi dalam hal ini UNINUS, pihak perusahaan yang ber operasi di kawasan hutan Darajat yaitu Star Energy Geothermal Darajat II Ltd., pengelola kawasan hutan lindung yaitu, PERHUTANI KPH Garut dan BP DAS HL, pengelola kawasan konservasi yaitu BBKSDA, Lembaga Masyarakat Desa Hutan., Lembaga Swadaya Masyarakat dan Pemerintah Daerah, sangat penting untuk terselenggaranya

$$
\text { Lingkungan Hidup dan Bencana }
$$


pengelolaan hutan yang lestari ( Rosmaladewi, 2017)

Tujuan dilaksanakan pengembangan agroforestry kopi organik di kawasan hutan Darajat yaitu untuk:1)Meningkatkan fungsi Kawasan Hutan, sehingga kawasan hutan dapat berfungsi secara ekologi, ekonomi dan sosial.

2)Pemberdayaan masyarakat yang tinggal di desa sekitar hutan Darajat dalam pengelolaan lingkungan khususnya dalam pelaksanaan rehabilitasi dan Konservasi kawasan hutan melalui pengembangan agroforestry kopi organik.3)Mengurangi Degradasi Sumberdayahutan dan lahan dan Peningkatan Keamanan Kawasan Hutan melalui Alih Komoditas, dan Alih Lokasi di lahan Kritis Kawasan Hutan Darajat.4)Penguatan kelembagaan Masyarakat Desa Hutan yang diiringi dengan meningkatnya management skill SDM melalui pendampingan yang intensif dari lembaga terkait.

5)Peningkatan jaringan kemitraan dalam upaya rehabilitasi hutan sehingga semua pihak berperan aktif sesuai dengan fungsinya.

6)Pendampingan Teknis \& Sosial terhadap LMDH.

\section{METODE}

Pengembangan Agroforestry kopi organikpada masyarakat desa di kawasan hutan Darajat merupakan program sinergitas yang dilaksanakan oleh Multistakeholder untuk mengurangi alih fungsi kawasan hutan, lindung Darajat agar berfungsi secara ekologi, ekonomi dan sosial.

Program ini dilaksanakan melalui pendekatan pengelolaan lingkungan, partisipatif, kemitraan dan berkelanjutan,

Metode yang dilaksanakan yaitu dengan cara :

a. Peningkatkan pengetahuan ketrampilan dan sikap masyarakat dan membangkitkan kesadaran mereka terhadap pentingnya pengelolaan dan pemanfaatan hutan yang bijaksana dengan tujuan kelestarian hutan. Selain itu untuk menggugah peran serta masyarakat agar mereka aktif dalam setiap kegiatan yang berhubungan dengan kelestarian lingkungan hutan untuk kelangsungan kehidupan generasi berikutnya.

b. Penguatan Kelembagaan LMDH

c. Pemberdayaan LMDH melalui usaha pembibitan kopi organik d. Bantuan bibit tanaman hutan, MPTS tanaman kopi dan sarana produksi dari pihak perusahaan yaitu Star Energy Geothermal Darajat II.Ltd melalui program Corporate Social Responcibility ( CSR) kepada masyarakat sasaran anggota Kelompok Tani Hutan dan Lembaga Masyarakat Desa Hutan

e. Rehabilitasi dan konservasi di lahan kritis dengan alih komoditas dan alih lokasi f0 Pengembangan Agroforestry kopi organik

f. Peningkatan Jaringan kemitraan dengan stakeholder

g. Pendampingan teknis dan sosial dari perguruan tinggi.

h. Pengamanan bersama kawasan hutan

\section{HASIL DAN PEMBAHASAN}

\section{Gambaran umum Masyarakat yang tinggal di sekitar Kawasan Hutan Darajat}

Kawasan Hutan Darajat berada di wilayah Kecamatan Pasirwangi Kabupaten Garut. Merupakan salah satu dari 42 kecamatan di Kabupaten Garut, dengan luas wilayah $4.670 \mathrm{Ha}$ dan jumlah penduduk sebanyak 58.182 jiwa Berdasarkan hasil kajian pendahuluan kondisi sosial ekonomi masyarakat Kecamatan Pasirwangi merupakan daerah agraris dengan mayoritas penduduknya 26.182 jiwa (45 \%) adalah petani. Sekitar 22.334 jiwa $(85,3 \%)$ dari golongan petani tersebut adalah buruh tani dan penggarap yang umumnya berpendidikan rendah dan hidup dibawah garis kemiskinan. Kebanyakan petani mengusahakan budidaya tanaman hortikultura seperti kentang, kubis dan tomat pada lahan yang terbatas dengan rata-rata luas lahan kurang dari 0,25 Ha. (Monografi Kecamatan Pasirwangi, 2009)

Sebagian besar buruh tani yang tidak mempunyai lahan dan tinggal di sekitar kawasan hutan Darajat, berusaha tani di kawasan hutan lindung bahkan merambah hutan konservasi. Usaha pertanian yang dilaksanakan yaitu tanaman hortikultura yang dikelola secara konvensional dan intensif. Hal ini menjadikan deforestasi kawasan hujan Darajat semakin

$$
\text { Lingkungan Hidup dan Bencana }
$$


tinggi yang berakibat terhadap penurunan fungsi kaawasan hutan dan rawan bencana alam.

Umumnya petani penggarap di kawasan Hutan Darajat melaksanakan budidaya tanaman hortikultura secara konvensional yaitu berdasarkan kebiasaan yang turun temurun. Penggunaan bibit, pupuk dan pestisida kimia dengan dosis yang kurang tepat dan tidak sesuai dengan aturan. Hal tersebut menjadikan biaya produksi yang tinggi pencemaran lingkungan dan terjadi degradasi sumber daya hutan.

Dengan kondisi yang digambarkan di atas maka sebagian besar masyarakat khususnya petani penggarap yang tinggal di kawasan hutan Darajat berada pada lingkaran kemiskinan, dan kehidupannya sangat tergantung kepada sumber daya hutan. Agar petani penggarap yang tinggal di kawasan hutan tersebut produktif, dan dapat melaksanakan konservasi sumberdaya hutan, maka kemitraan multistakeholder dalam pengembangan agroforestry kopi organik di Kawasan Hutan Darajat sangat penting dilaksanakan,

\section{Kemitraan Multistakeholder dalam Pengembangan Agroforestry kopi organik di Kawasan Hutan Darajat}

Dengan semakin menurunnya daya dukung sumber daya hutan maka diperlukan system pengelolaan kawasan hutan yang komprehensif, partisipatif dan berkelanjutan yang fokus kepada kelestarian lingkungan dan pemberdayaan masyarakat yang tinggal di sekitar kawasan hutan Darajat.

Seiring dengan permintaan kopi Arabika yang tiap tahun terus meningkat, yang menuntut masyarakat Kabupaten Garut meningkatkan produksinya. Seperti dikutip dalam Tempo.co edisi 15 Oktober 2017, Pemerintah turut membantu dalam upaya pengembagan dan peningkatan produksi kopi, yakni melalui Kementerian Lingkungan Hidup dan Kehutanan menawarkan lahan hutan bagi petani untuk menanam kopi. Menurut BBPP Lembang (2016) kopi jenis Arabika sangat baik ditanam di daerah yang berketinggiana 1.000-2.100 meter di atas permukaan laut (dpl). Lahan dengan ketinggian itu tentu berada di kawasan hutan lindung milik pemerintah. Karena itu, Kementerian sangat mendorong para petani untuk mulai memaksimalkan potensi lahan dengan cara Agroforestry berbasis kopi organik. Berdasarkan kondisi lingkungan dan masyarakat yang tinggal di sekitar hutan Darajat maka alih komoditas melalui pengembangan agroforestry kopi organik merupakan strategi yang paling sesuai dalam mengurangi alih fungsi kawasan hutan, hutan lindung dengan tetap memberdayakan petani.

Kemitraan multistakeholder dalam pengembangan agroforestry kopi organik merupakan upaya dalam peningkatan fungsi kawasan hutan, agar Kawasan Hutan Darajat dapat berfungsi secara ekologi, ekonomi dan sosial. Kemitraan yang dilaksanakan antar pihak Perguruan tinggi,yaitu UNINUS melalui program pengabdian masyarakat, pihak perusahaan Star Energy Geothermal Darajat II melalui program Corporate Social Responcibility (CSR) , Perhutani KPH Garut yang merupakan BUMN yang bergerak di bidang kehutanan., Pemerintah Daerah, dan Lembaga Masyarakat Desa Hutan ( LMDH) untuk terselenggaranya pengelolaan sumber daya hutan yang lestari.

Kemitraan yang dilaksanakan dalam program pengembangan Agroforestry kopi organik melalui pengintegrasian program, kontribusi sumber daya masing-masing lembaga, berbagi kepakaran dan pendampingan teknik dan social. Semua itu dilaksanakan untuk meningkatkan fungsi kawasan hutan dan pemberdayaan masyarakat yang tinggal di sekitar kawasan hutan.

Pengembangan Agroforestry kopi organik pada masyarakat desa yang tinggal disekitar Kawasan Hutan Darajat dilaksanakan juga sebagai sistem pengamanan kawasan untuk pelestarian sumber daya hutan. Program dilaksanakan berdasarkan azas pemberdayaan masyarakat dan pengelolaan sumberdaya hutan melalui kemitraan multi stakeholder. Program ini merupakan salah satu alternatif yang dapat dilakukan dalam mengurangi alih fungsi kawasan hutan dan mengurangi bencana alam. yang dilaksanakan secara sistematis, partisipatif dan berkelanjutan.

$$
\text { Lingkungan Hidup dan Bencana }
$$


Pengembangan Agroforestry kopi organik dilaksanakan sebagai perlindungan sumber daya hutan dengan menekan laju kerusakan hutan terutama akibat perambahan dengan pendekatan pengelolaan hutan bersama multistakeholder sehingga kawasan hutan dapat kembali berfungsi secara optimal

Pengembangan Agroforestry kopi organik juga merupakan upaya pemberdayaan masyarakat yang tinggal disekitar hutan Darajat untuk meningkatkan kesejahteraan masyarakat sebagai wujud tanggung jawab sosial dan lingkungan

Program yang dilaksanakan secara terintegrasi dan terpadu dimulai dari inventarisasi sumberdaya alam dan hutan. Pemetaan kondisi sosial ekonomi masyarakat desa hutan, perencanaan bersama pengelolaan kawasan hutan dengan melibatkan stakeholder melaksanakan program penyadaran pengelolaan lingkungan berbasis masyarakat, melaksanakan rehabilitasi dan konservasi di lahan yang kritis melalui alih komoditas dan alih lokasi. Pendampingan teknis dan sosial, Monitoring dan evaluasi dilaksanakan secara bersama dan berkala serta pengamanan kawasan hutan dilaksanakan secara bersama. Semua kegiatan dilaksanakan agar kawasan hutan dapat berfungsi secara ekologi, sosial dan ekonomi dengan jiwa bersama dan berbagi, untuk kepentingan bersama. Yaitu untuk mencapai keberlanjutan fungsi dan manfaat sumberdaya hutan yang dapat diwujudkan secara optimal dan proporsional.

\section{KESIMPULAN}

Alih fungsi Kawasan Hutan Darajat yang terjadi secara massif di daerah hulu menjadikan sumberdaya hutan terus menurun. Untuk hal tersebut rehabilitasi dan konservasi kawasan hutan melalui pengembangan Agroforestry kopi organik sangat diperlukan. Yaitu dengan membangun system pengelolaan kawasan hutan bersama multistakeholder yang komprehensif, partisipatif dan berkelanjutan dengan pendekatan kemitraan, pemberdayaan masyarakat, dan kelestarian lingkungan.

\begin{abstract}
Pengelolaan
Hutan

Bersama

Multistakeholder melalui Pengembangan Agroforestry Kopi Organik dilaksanakan dengan jiwa bersama dan berbagi, untuk kepentingan bersama yaitu mencapai keberlanjutan fungsi dan manfaat sumberdaya hutan yang dapat diwujudkan secara optimal dan proporsional. Sehingga kawasan hutan dapat berfungsi secara ekologis, ekonomis, dan sosial
\end{abstract}

Program yang dilaksanakan secara terintegrasi dimulai dari inventarisasi sumberdaya alam \& hutan, Pemetaan kondisi sosial ekonomi masyarakat desa hutan, perencanaan bersama pengelolaan kawasan hutan dengan melibatkan stakeholder, melaksanakan program penyadaran pengelolaan lingkungan berbasis masyarakat, melaksanakan rehabilitasi dan konservasi di lahan yang kritis melalui alih komoditas tanaman hortikultura menjadi tanaman hutan, Multi purpuses spesies dan tanaman kopi organik serta alih lokasi, Pendampingan teknis dan sosial, Monitoring dan evaluasi secara bersama dan berkala. Semua itu dilaksanakan untuk mengembalikan fungsi dan manfaan kawasan hutan sehingga menjadi hutan yang hijau lestari dan aman dari bencana alam.

Pengelolaan Hutan Bersama Multistakeholder melalui Pengembangan Agroforestry Kopi Organik dilaksanakan sebagai upaya pelestarian sumber daya hutan berdasarkan azas pemberdayaan masyarakat, pengelolaan lingkungan dan pengamanan serta perlindungan sumber daya hutan. Yaitu dengan menekan laju kerusakan hutan terutama akibat perambahan untuk mengurangi alih fungsi kawasan hutan dan mengurangi bencana alam. yang dilaksanakan secara sistematis, partisipatif dan berkelanjutan. sehingga kawasan hutan dapat kembali berfungsi secara optimal

\section{Rekomendasi}

Lebih menselaraskan kegiatan pengelolaan sumber daya hutan yang sesuai dengan karakteristik dan kegiatan pembangunan wilayah, terutama dalam program pemberdayaan masyarakat desa hutan. Oleh karena itu perlu dilaksanakan pengembangan pola kemitraan dengan lembaga/instansi lain sehingga dapat meningkatkan fungsi dan manfaat sumberdaya hutan.

Rehabilitasi dan Konservasi kawasan hutan dilaksanakan secara bertahap diprioritaskan di lahan

$$
\text { Lingkungan Hidup dan Bencana }
$$


yang kritis sebagai upaya preventif dalam penanggulangan bencana longsor, banjir dan kebakaran hutan.

Meningkatkan sinergitas dalam pengelolaan kawasan hutan dengan mengacu kepada peraturan dan pedoman pelaksanaan yang dikeluarkan oleh lembaga yang berwenang dalam hal ini Kementrian Lingkungan Hidup dan kehutanan.

\section{UCAPAN TERIMAKASIH}

Ucapan terimakasih dan penghargaan yang setinggi tinggi nya disampaikan kepada LPPM Universitas Islam Nusantara, Star Energy Geothermal Darajat II.Limited, Perhutani KPH Garut, BP DAS HL Jabar, Lembaga Masyarakat Desa Hutan Mekar Lestari

\section{REFERENSI}

Balai Besar Pelatihan Pertanian Lembang. 2016. Mengenal Tanaman Kopi. Tersedia pada laman http://www.bbpplembang.info (diakses pada tanggal 12 juni 2019)

\section{Keputusan Menteri Kehutanan Nomor 195/KPTS-II/ $2003 \quad$ Tentang Penunjukan Kawasan Hutan di Provinsi Jawa Barat seluas +/- 816.603 $\mathrm{Ha}$}

Keputusan Direksi Perum Perhutani No: 268/KPTS/DIR/2007 tentang Pedoman Pengelolaan Sumberdaya Hutan Bersama Masyarakat Plus (PHBM PLUS)

Monografi Kecamatan Pasirwangi, 2009

Okke Rosmaladewi Rubi Robana Lilis Irmawatie 2015 ， Development
Partnership model As Multistakeholder Community Forest Management in The Darajat Foresat Area Garut District International Journal of Research in Agriculture and Forestry Volume X, Issue X, Month 2015, PP XXXX ISSN 2394-5907 (Print) \& ISSN 2394-5915 (Online)

Okke Rosmaladewi Ibrahim Danuwikarsa Panji Pranadikusumah, 2017. Pengelolaan Hutan Bersama Multistakeholder sebagai Pelaksanaan Corporate Social Responcibility . Jurnal Pengabdian Masyarakat Vol 7 no 1 Agustus 2017. P-ISSN 2088-6977 E-ISSN 2584-1487

Perum Perhutani, KPH Garut 2007, Potensi Sumberdaya Hutan KPH Garut, Perum Perhutani Unit III Jawa BaratBanten. Bandung.

Supriadi, H., dan Pranowo, D. 2015. Prospek Pengembangan Agroforestri Berbasis Kopi di Indonesia. Perspektif Vol. 14 No. 2 /Des 2015. Hlm 135 -150 ISSN: 1412-8004

Tempo.co. KLHK Tawarkan Hutan untuk Tanam Kopi dengan Sistem Agroforestri. Edisi Minggu 15 Oktober 2017. Tersedia pada laman https://bisnis.tempo.co (diakses pada tanggal 12 Juni 2019)

Undang Undang Republik Indonesia no 41 tahun 1999 Tentang Kehutanan 